\title{
Spraakverstaan, taalvaardigheid en verbaal werkgeheugen bij kinderen met $\mathrm{CI}$
}

\author{
Margreet Langereis $^{1}$, Wouter Rijke ${ }^{2,3}$, Anneke Vermeulen ${ }^{1}$ \\ ${ }^{1}$ Pento Audiologische Centra, Utrecht \\ ${ }^{2}$ Radboudumc, Health Technology Assessment, Nijmegen \\ ${ }^{3}$ Koninklijke Kentalis, Diagnostisch Centrum, St Michielsgestel
}

\begin{abstract}
Samenvatting
Dit artikel is geschreven ten behoeve van het NVSST symposium 'to hear or not to hear', 1 maart 2019.

Met een cochleair implantaat (CI) worden de spraakperceptiemogelijkheden in rust van ernstig slechthorende en dove kinderen aanzienlijk verbeterd. In ongunstige luistersituaties zijn de hoormogelijkheden nog beperkt.

De auditieve mogelijkheden met CI bieden in principe voldoende voorwaarde voor de verwerving van een leeftijdsadequaat woordbegrip. Echter op het gebied van complexere taalvaardigheden zoals morfo-syntaxis, vertelvaardigheden en verbaal redeneren worden nog problemen beschreven.

Een mogelijke verklaring daarvoor, naast het verminderde spraakverstaan, is gelegen in de zwakkere en instabiele fonologische representaties. Er blijken vooral problemen met de storage component (fonologische loop) van het werkgeheugen. Dit heeft tot gevolg dat de capaciteit en de effectiviteit van het werkgeheugen verminderen.
\end{abstract}

\section{Summary}

This manuscript is written as a supplement on the occasion of the NVSST symposium 'to hear or not to hear', 1 March 2019.

With a cochlear implant (CI), the speech perception abilities in quiet of severely hearingimpaired and deaf children have considerably improved. In unfavorable listening situations, the hearing abilities remain still limited.

In principle, the auditory perception with CI offers sufficient conditions for the acquisition of an age-appropriate word comprehension. However, problems are still described in the area of more complex language skills such as morpho-syntax, narrative skills and verbal reasoning.

A plausible explanation, apart from impaired speech perception, is found in weaker and unstable phonological representations. This affects the storage component (phonological loop) of the working memory. As a result, the capacity and effectiveness of the working memory decreases.

Correspondentieadres:

Dr. M. Langereis

Pento Audiologisch Centrum

Burgemeester Verderlaan 15

3544 AD Utrecht

E-mail: m. langereis@pento.nl
Dit artikel is gelicentieerd onder de Creative Commons CC BY-NC-ND 4.0 (NaamsvermeldingNietCommercieel-GeenAfgeleideWerken) Internationale Licentie. Gebruik en distributie voor commerciële doeleinden en elke distributie van aangepast materiaal vereist schriftelijke toestemming. 


\section{Inleiding}

Dit artikel 'Kinderen met CI: spraakverstaan, taalvaardigheid en werkgeheugen' is geschreven ten behoeve van het themanummer ter gelegenheid van het NVSST symposium 'to hear or not to hear', 1 maart 2019. Het artikel beschrijft allereerst de uitkomstmaten en richt zich vervolgens op de onderliggende processen.

\section{Impact van hoortoestellen en cochleaire implants op het spraakverstaan}

Een belangrijke voorwaarde voor de vanzelfsprekende verwerving van gesproken taal is de mogelijkheid om spraakklanken auditief te onderscheiden. De ontwikkeling van gesproken taal is hierdoor bij kinderen met een auditieve beperking belemmerd.

Voor kinderen met ernstige beiderzijdse gehoorverliezen, dat wil zeggen verliezen in de hoge frequenties van $>85 \mathrm{~dB}$ HL, wordt sinds begin 2000 cochleaire implantatie (CI) toegepast. Hierdoor is het auditieve spraakverstaan van deze kinderen aanzienlijk verbeterd ten opzichte van de mogelijkheden die hoortoestellen hen voorheen boden. Dit wordt uitgedrukt in het percentage correct herhaalde fonemen van monosyllabische CVC-woorden (Bosman \& Smoorenburg, 1995). Er bestaat een duidelijk verband tussen de aard en de mate van het gehoorverlies en het percentage geïdentificeerde fonemen bij kinderen met hoortoestellen. Voor de toepassing van CI waren kinderen met ernstige gehoorverliezen met hoortoestellen nauwelijks in staat tot het waarnemen van spraakklanken. Naarmate het gehoorverlies toenam, nam het spraakverstaan significant af. Dit bleek uit de resultaten van spraakverstaan van 120 prelinguaal slechthorende en dove kinderen (mediane Fletcher Index $=102$ ) beschreven door Boothroyd (1984). De subgroep met verliezen tussen 55 en $74 \mathrm{dBHL}$ bereikte een gemiddelde score van $66 \%$, de subgroep met verliezen van 75 tot 89 dBHL een gemiddelde van $47 \%$ en de subgroep met nog grotere verliezen kwam nauwelijks tot spraakverstaan. Ondanks de technische verbeteringen van de hoortoestellen en vroege interventie behaalden kinderen met deze ernstige verliezen nog relatief ongunstige spraaksverstaansscores in vergelijking met de mogelijkheden die CI biedt.

De eerste positieve gegevens over de mogelijkheden tot spraakverstaan met een CI werden vermeld in een studie van Meyer, Svirsky, Kirk en Miyamoto (1998). Deze liet zien dat de spraakverstaanscores van dove kinderen, met verliezen van > $120 \mathrm{dBHL}$, met CI gunstiger lagen dan die van kinderen met ernstige gehoorverliezen die bilaterale hoortoestellen gebruikten. De scores van kinderen benaderden de scores van hoortoestel-gebruikers met verliezen van 90-100 dBHL. Recentere gegevens over de mogelijkheden van ernstig auditief beperkte kinderen met CI daarentegen laten eenduidig veel gunstiger scores zien, zelfs vergelijkbaar met die van kinderen met matige gehoorverliezen die hoortoestellen gebruiken. Deze verbetering is het gevolg van implantatie op jongere leeftijd, de toepassing van bilaterale CI, de technische evolutie en verbreding van de auditieve inclusiecriteria, waar- 
door kinderen met meer restgehoor, dus met betere auditieve structuren, ook in aanmerking kwamen. Eisenberg, Kirk, Martinez, Ying en Miyamoto (2004) toonden aan dat 117 dove kinderen met CI vergelijkbaar scoorden (82\%) met de bovengenoemde groepen matig slechthorende kinderen. Dit werd recent ook bevestigd in de studie van Torkildsen, Hitchins, Myhrum en Wie (2019) die foneemscores van gemiddeld $87 \%$ voor de CI groep en $88 \%$ voor de hoortoestelgroep van met name matig slechthorende kinderen vermeldden.

Ongeacht het feit dat met CI('s) het spraakverstaan in gunstige luisteromstandigheden sterk is toegenomen in vergelijking met het gebruik van hoortoestellen bij dezelfde doelgroep, ervaren deze kinderen toch nog aanzienlijke problemen bij het verstaan in ongunstige luistersituaties. Dit is vooral het geval bij kinderen met een unilaterale aanpassing. Luisteren met twee oren is beter dan met één, want de luisteraar kan selectief luisteren naar het oor met de gunstigste spraak in ruis verhouding om beter te verstaan. Daarnaast is er een binauraal voordeel van het integreren van de informatie van beide afzonderlijke oren. Dit heeft een positief effect voor het spraakverstaan in ruis en het richtinghoren. Er zijn diverse studies waarin deze binaurale voordelen beschreven worden (Litovsky \& Gordon, 2016). In de studie van Torkildsen e.a. (2019) werd ook onderzoek in ruis verricht. Relatief goed presterende kinderen met bilaterale CI of hoorapparatuur behaalden een SNR score van 2,6 dB, terwijl normaalhorenden gemiddeld -2,9 scoorden. Dit betekent dat zelfs optimaal presterende CI gebruikers in dagelijkse rumoerige situaties belemmeringen zullen ervaren in de auditieve communicatie.

\section{Relatie tussen spraakverstaan in rust en verwerving van ba- sale taalvaardigheden}

De betere auditieve mogelijkheden met CI hebben voor de doelgroep een duidelijk effect gehad voor de ontwikkeling van gesproken taal.

De mate van gehoorverlies was voorheen bepalend voor het spraakverstaan en de taalvaardigheid. Gegevens van Tomblin, Harrison, Ambrose, Walker, Oleson en Moeller (2015) laten zien dat bij slechthorende kinderen (gemiddelde Fletcher Index van 46,6 dB HL) met hoorapparatuur nog een associatie gevonden wordt tussen de mate van gehoorverlies en de taalvaardigheid. Zoals verwacht mag worden biedt het toegenomen spraakverstaan met CI gunstiger voorwaarden voor de gesproken taalverwerving. Vrijwel alle ernstig slechthorende kinderen met CI behalen goede spraakverstaanscores in stilte. Een foneemscore in rust van ca $85 \%$ lijkt de kinderen zonder bijkomende (leer)problemen in staat te stellen tot het verwerven van een leeftijdsadequaat woordbegrip (Langereis \& Vermeulen, 2013).

Svirsky, Teoh en Neuburger vonden in 2004 een duidelijke relatie tussen de leeftijd bij implantatie en de receptieve woordenschat. Hoe jonger bij implantatie en dus hoe kleiner de opgelopen taalachterstand, des te gunstiger het uiteindelijke taalniveau omdat het kind eerder een beter spraakverstaan bereikt. 


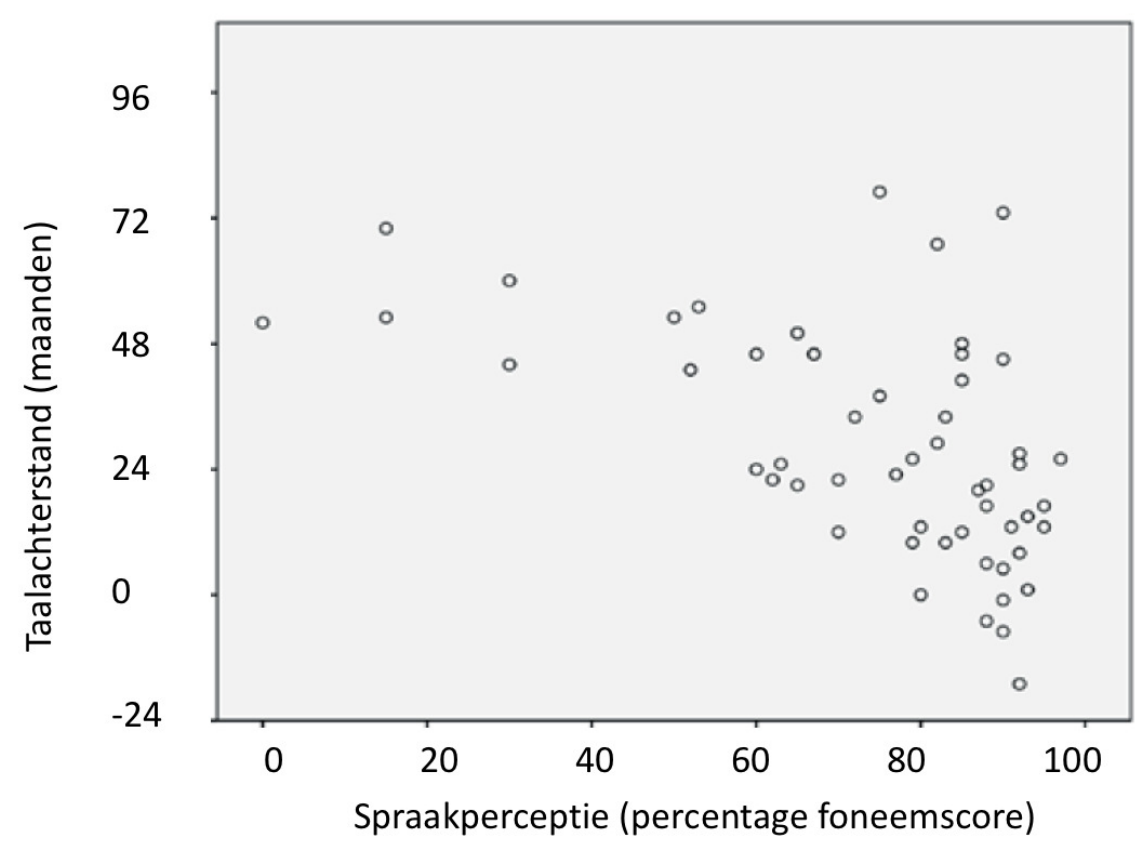

Figuur 1: De relatie tussen spraakverstaan in stilte en het woordbegripsquotient. Uit: Langereis \& Vermeulen (2013).

Zoals zichtbaar in Figuur 1 is auditieve toegankelijkheid van gesproken taal noodzakelijk maar niet voldoende voor ontwikkeling van de gesproken taal. Naast auditieve toegankelijkheid tot gesproken taal zijn natuurlijk een voldoende kwantitatief en kwalitatief taalaanbod noodzakelijk. Busch, Vermeulen, Langereis, Vanpoucke en Van Wieringen (2019) beschrijven het belang van consistent CI gebruik en een rijk auditief aanbod voor de vroege taalontwikkeling. Zij vonden een positieve samenhang tussen mate van blootstelling aan auditieve input en het woordbegrip bij 52 kinderen met CI.

Er is op grote schaal onderzoek gedaan naar het positieve effect van een rijke communicatieve en talige omgeving op de taalverwerving van kinderen met CI. Zo laten bijvoorbeeld Desjardin en Eisenberg (2007) zien dat het geloof in eigen kunnen als opvoeder, van ouders positief geassocieerd was met de kwaliteit van hun interactievaardigheden. Verder vonden zij een positieve relatie tussen de taalvaardigheid van het kind met zowel mate van het gebruik van faciliterende taaltechnieken als de gemiddelde uitingslengte in het taalgebruik van de moeder. De meta analyse van Holzinger, Dall, Sanduvete-Chaves, Saldaña, ChacónMoscoso en Fellinger (2020) onderschrijft eveneens de hypothese dat het linguïstisch aanbod van ouders in de eerste jaren na CI heel sterk de latere taalmogelijkheden van het kind bepaalt. 


\section{Relatie tussen spraakverstaan in ongunstige luistersituaties en complexe taalvaardigheden}

Een voldoende spraakverstaan en taalaanbod leiden over het algemeen tot een leeftijdsadequaat woordbegrip. Echter, op het gebied van complexere taalvaardigheden zoals verbaal redeneren, vertelvaardigheden en de morfosyntax worden in de meeste studies bij kinderen met een auditieve beperking resultaten gevonden die gemiddeld beneden de norm liggen. Er is echter sprake van een zeer grote variantie, een relatief kleine groep presteert leeftijdsadequaat. Over het algemeen gelden betere mogelijkheden tot verstaan in complexe luisteromstandigheden als een gunstige voorwaarde. In meerdere studies wordt uiteraard gevonden dat naast de auditieve input andere factoren het taalniveau bepalen. Dat wil zeggen dat een lager taalniveau niet rechtstreeks toegeschreven kan worden aan verminderde perceptuele accentuering binnen het signaal maar waarschijnlijk ook aan zwakke onderliggende fonologische representaties. Daarnaast blijven factoren die relevant zijn voor de taalontwikkeling bij normaalhorende kinderen natuurlijk ook van invloed.

\section{Verbaal redeneren}

Een eerste complex taaldomein is het verbaal redeneren. Bepaling van de verbale cognitie als onderdeel van een bredere intelligentie was voor de toepassing van CI nauwelijks mogelijk bij kinderen met een ernstige auditieve beperking, die niet of nauwelijks gesproken taalvaardig waren. Het profiel van kinderen met een auditieve beperking liet daarom vrijwel altijd een hogere performale intelligentie zien (Geers \& Sedey, 2011). Onderzoeken waarbij het verbaal intelligentie quotient (VIQ) in kaart is gebracht laten een erg grote spreiding zien, waarbij ca $56 \%$ van de basisschoolkinderen binnen 1 sd van het gemiddeld scoort (Geers, Strube, Tobey, Pisoni, \& Moog, 2011). De gunstigste scores worden gevonden bij kinderen die bilaterale CI gebruiken. De Raeve, Vermeulen en Snik (2015) vonden bij kinderen met unilaterale CI een gemiddeld VIQ van 74 en bij bilaterale CI 92. In de studie van Jacobs, Langereis, Frijns, Free, Goedegebure, Smits, Stokroos, Ariens-Meijer, Mylanus en Vermeulen (2016) worden vergelijkbare bevindingen vermeld, gemiddeld VIQ van 78 voor uni- en 93 voor kinderen met bilaterale CI. De twee laatstgenoemde studies laten zien dat er een positieve samenhang is tussen het spraakverstaan in complexe luistersituaties en het VIQ. Deze relatie is weergegeven door De Raeve e.a. (2015) in Figuur 2 en toont de relatie tussen verstaan van zachte spraak en het VIQ, De kinderen met bilaterale CI hebben als gevolg van binauraal horen meer toegang tot incidentele leerprocessen. Binauraal horen leidt tot minder luisterinspanning waardoor minder belasting zal zijn van cognitieve resources zoals het werkgeheugen. Er is een mediërende rol van het auditieve kortetermijngeheugen aangetoond tussen het spraakverstaan in ruis en het VIQ voor kinderen met CI in het reguliere onderwijs in de studie van Jacobs.

\section{Vertelvaardigheden}

Een tweede complexe taalvaardigheid waarvan is beschreven dat kinderen met CI er nog moeite mee hebben zijn de vertelvaardigheden. De vertelvaardigheden worden veelal uit- 


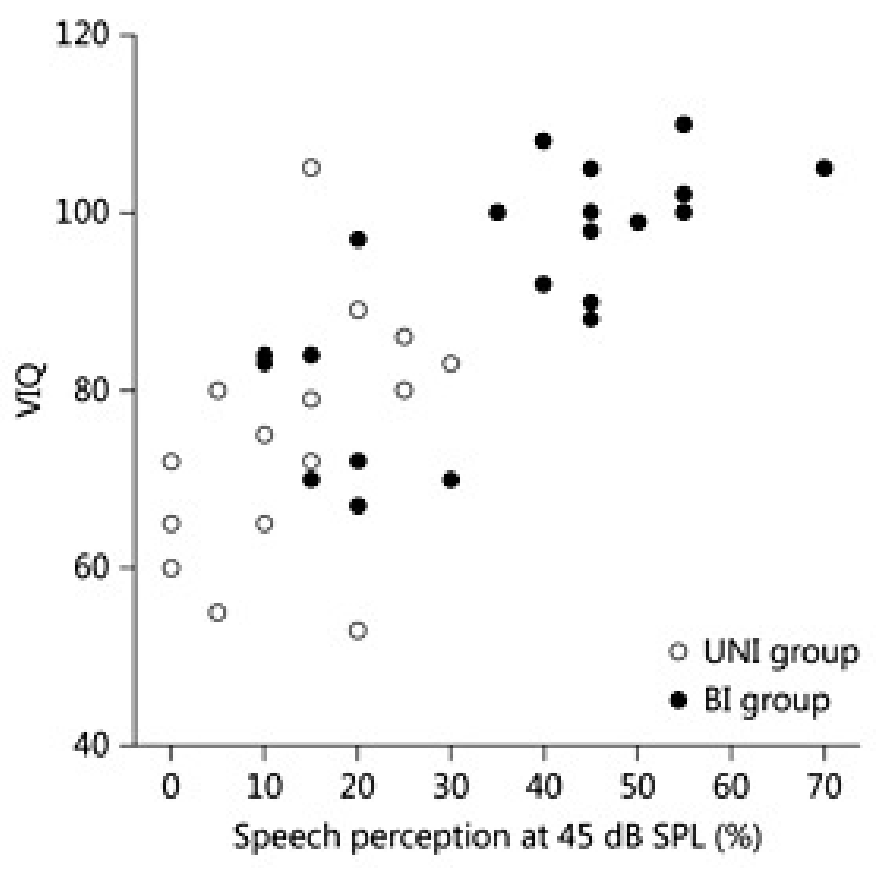

Figuur 2: De relatie tussen verstaan van zachte spraak en verbaal IQ van kinderen met uni- of bilaterale CI. Een gemiddeld IQ varieert van 90 tot 110. Uit: De Raeve e.a. 2015.

gedrukt in de mogelijkheid van het weergeven van de verhaalstructuur en de grammaticale vaardigheden daarvoor. Crosson en Geers (2001) hebben de narratieve vaardigheden van 87 8- tot 9-jarige kinderen met CI vergeleken met die van horende leeftijdsgenoten. In dit artikel is vooral gekeken naar de verhaalstructuur. De CI kinderen met relatief goede hoormogelijkheden lieten een vergelijkbare plotstructuur en cohesie zien als de horende kinderen. De kinderen met CI gebruikten echter minder onderschikkende voegwoorden. Boons e.a. (2013) hebben de narratieve vaardigheden van 66 kinderen met CI onderzocht, in de leeftijd van 5 tot en met 13 jaar, met de Renfrew BusStoryTest. Op macroniveau vonden zij dat alle plotelementen minder compleet verwoord werden. Op microniveau bleek dat kinderen met CI een vergelijkbaar aantal uitingen gebruikten, echter de gemiddelde uitingslengte en het aantal ondergeschikte bijzinnen bleven achter. Ook produceerden kinderen met CI aanzienlijk meer grammaticaal incorrecte uitingen. De kinderen die voor de leeftijd van 2 jaar bilaterale CI kregen, geen bijkomende problemen hadden en een eentalige opvoeding genoten hadden, behaalden een taalniveau vergelijkbaar met horende leeftijdsgenoten.

\section{Morfo-syntactische vaardigheden}

Ten derde worden er bij kinderen met CI nog problemen gerapporteerd op het gebied van morfo-syntax. Boons e.a. (2013) beschreven de expressieve grammaticale ontwikkeling van 70 kinderen in de basisschool leeftijd (5-13 jaar). De mediaan, die voor de normgroep gelijk is aan 1 , was voor de kinderen met CI op alle taaldomeinen ca 0,82. De spreiding was het 
grootst voor de syntaxis en de morfologie. Bijkomende problemen en meertaligheid hadden een negatieve invloed op zowel de woordenschat als grammatica. Kinderen die vroege interventie hadden gehad met aanpassing van bilaterale aanpassingen lieten daarentegen betere resultaten zien. Uit onderzoek van Sarant, Harris, Bennet en Bant (2014) bij 91 kinderen van 5 of 8 jaar, met uni of bilaterale CI bleek dat kinderen met bilaterale CI en optimale thuis en onderwijsomgeving gemiddeld scores behalen die vergelijkbaar zijn met de norm, zowel op het gebied van het woordbegrip als dat van taalvaardigheden gemeten met de diverse CELF onderdelen. In 2015 vermeldde Sarant over 44 8-jarige kinderen met CI lagere schoolse prestaties dan gemiddeld, waarbij bilaterale implantatie op jonge leeftijd en betrokkenheid van de ouders belangrijke factoren voor succes waren. Vergelijkbare ontwikkelingen werden gesignaleerd door Tomblin e.a. (2015) in een studie over 290 licht tot ernstig slechthorende kinderen in de leeftijd van 2 tot 6 jaar. Ook deze groep kinderen liet achterstanden in de taalontwikkeling zien, waarbij de semantiek minder ver achter was dan de morfo-syntaxis. Kinderen met gunstigere hoormogelijkheden lieten gunstigere groei zien. Kinderen waarbij vroegtijdige hoorapparatuuraanpassing had plaatsgevonden hadden de meest optimale mogelijkheden. Onderzoek van Van Weerdenburg, De Hoog, Knoors, Verhoeven en Langereis (2019) naar de morfo-syntax bij 58 kinderen, van 6 tot en met 11 jaar, die gemiddeld op relatief late leeftijd een CI kregen, vermeldt dat zowel bij de receptieve als de expressieve vaardigheden gemeten met het Testinstrumentarium TOS, receptieve en expressieve woordenschat, receptieve syntax en expressieve morfologie, auditief geheugen voor zinnen (Verhoeven, Keuning, Horsels, \& Boxtel, 2013) de resultaten achterblijven. De spreiding is groot, vanaf minus 3 sd tot gemiddeld. Zij concluderen dat naast het beperkte auditieve spraakverstaan auditieve verwerkingsproblemen daarbij een rol spelen. Daarnaast vergeleken De Hoog, Langereis, Van Weerdenburg, Knoors en Verhoeven (2016) de taalprofielen van kinderen met een auditieve beperking met die van kinderen met een taalontwikkelingsstoornis in de leeftijdscategorie van 6 tot 11 jaar. Ze vonden dat er in de bij de jongere kinderen 6-8 jaar met een auditief probleem $25 \%$ bleek te zijn waarvan het taalprofiel overeenkwam met dat van de kinderen met TOS. Dit profiel wordt gekenmerkt door een zwakker werkgeheugen en een relatief gunstiger spraakverstaan. Anderzijds was er in de groep van kinderen met een TOS ook ongeveer een kwart van de kinderen waarvan het taalprofiel overeenkwam met dat van de auditief beperkte kinderen, waarbij er sprake was van een relatief zwakker spraakverstaan en een relatief gunstiger werkgeheugen. Dit is weergegeven in Figuur 3.

Guo en Spencer (2017) onderzochten de grammaticale ontwikkeling gedetailleerd in een verteltaak bij 10 kinderen met CI van 4, 5 en 6 jaar. De kinderen met CI maakten over het algemeen kortere zinnen dan horende kinderen die gematched waren op hoorleeftijd. Kinderen met betere hoormogelijkheden maakten langere uitingen. Hoewel dus kinderen met CI niet vergelijkbaar presteerden met de leeftijd-gematchte groep waren de grammaticale foutenpatronen wel vergelijkbaar. Bij kinderen met CI werd gevonden dat als de voorwaarden gunstig waren er een lichte achterstand in de grammaticale accuratesse was. De auteurs vermelden twee mogelijk verklarende factoren. Ten eerste zijn er mogelijk beperkingen in het spraakverstaan, waardoor onopvallende grammaticale markers niet worden waargenomen. Ten tweede zou de verklaring kunnen liggen in de zwakke fonologische representaties 


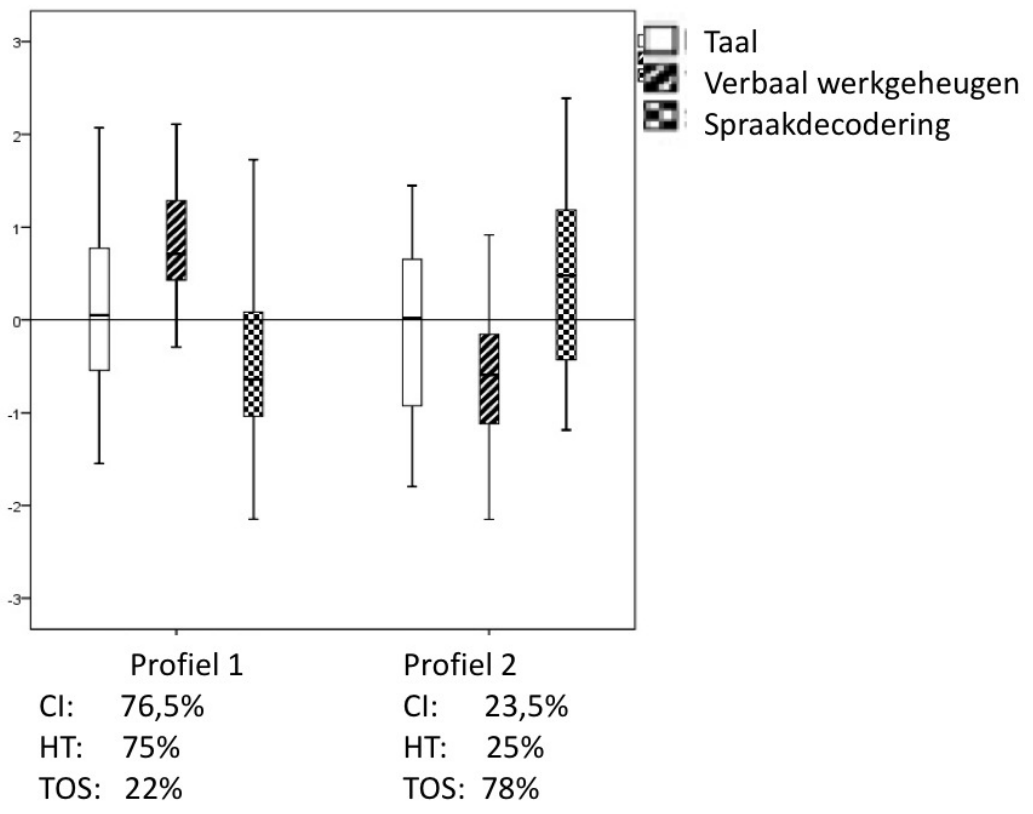

Figuur 3: Twee verschillende taalprofielen met de betreffende percentages van de jonge slechthorende kinderen (met CI of hoortoestel (HT) en kinderen met taalontwikkelingsstoornissen die dit profiel vertonen. Uit: De Hoog e.a. 2016.

bij kinderen met CI, welke ten gevolge van suboptimale auditieve input minder stabiel ontwikkeld zijn.

\section{Verbaal werkgeheugen}

De oorzaken van minder stabiele fonologische representaties in het werkgeheugen, die de complexe taalontwikkeling kunnen belemmeren zijn in meerdere studies bestudeerd. Diverse studies hebben aangetoond dat een langere periode van auditieve deprivatie kan leiden tot ontstaan van instabielere fonologische representaties of degeneratie van bestaande representaties. Daarnaast is aangetoond dat met gebruik van CI deze representaties niet adequaat kunnen worden hersteld (Moberly, Patel, \& Castellanos, 2018). Deze zwakke fonologische representaties kunnen tot gevolg hebben dat de werkgeheugencapaciteit en efficiëntie verminderen.

Het verbale werkgeheugen is een tijdelijk opslagmechanisme met een gelimiteerde capaciteit (Baddeley \& Hitch, 1974) waarbij een 'storage' en een 'processing' component betrokken zijn. Talige informatie word door herhaling in de fonologische loop beschikbaar gehouden (storage) voor verdere verwerking (processing). Het verwerken van gesproken taal, auditief en linguïstisch, doet een beroep op het verbale werkgeheugen. Een verminderd werkgeheugen kan een negatieve invloed hebben op spraakperceptie en woordherkenning 
(Moberly, Harris, Boyce, \& Nittrouer, 2017; Pisoni, Kronenberger, Roman, \& Geers, 2011). Er blijkt dat werkgeheugenproblemen bij kinderen met CI vooral het gevolg zijn van problemen in de 'storage-component' (Cleary, Pisoni, \& Geers, 2001; Nittrouer, Caldwell-Tarr, \& Lowenstein, 2013). Recente resultaten van Rijke, Vermeulen, Willeboer, Knoors, Mylanus, Langereis \& Van der Wilt (concept manuscript 2020) van onderzoek bij 23 kinderen tussen 8 en 12 jaar die CI gebruiken, bevestigen de storage problemen bij kinderen met CI. Hun fonologische verwerkingsvaardigheden onderzocht met een non-woordrepetitietest bleken eveneens zwak. Overeenkomstig bovenstaande studies bleek dat vooral de storage component (voorwaarts cijfers herhalen) zwak was en de processing (achterwaarts cijfers herhalen) gemiddeld (Figuur 4). De storage component laat een zwakke associatie met de linguïstische vaardigheden zien ( $\mathrm{rs}=.391, \mathrm{p}=.032$ ), deze is weergegeven in Figuur 5. Bovendien behaalden de kinderen wel relatief goede spraakverstaansvaardigheden in rust, maar in rumoerige luisteromstandigheden, zelfs bij relatief gunstige spraak-in-ruisverhoudingen $(\mathrm{SNR}=0)$, daalde het spraakverstaan significant. Dit betekent dat zij veel luisterinpanning moeten leveren, hetgeen ook een beroep doet op de, al beperkte, werkgeheugencapaciteit (Peelle, 2018). Deze studie bevestigt duidelijk dat het werkgeheugen van kinderen met CI een afwijkende ontwikkeling laat zien zoals ook beschreven door Pisoni e.a. (2011) en Watson, Tittering, Henry en Toner (2007).

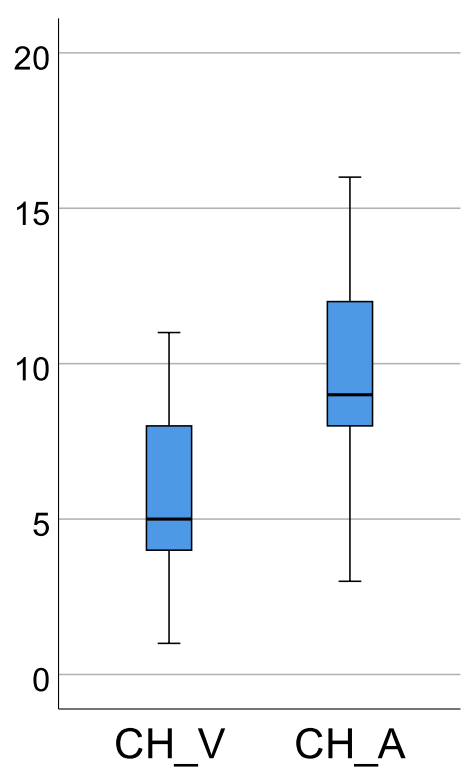

Figuur 4: De boxplots van de CELF onderdelen Cijfers Herhalen Voorwaarts (CH_V) en Cijfers Herhalen Achterwaarts (CH_A) bij kinderen met CI. Een gemiddelde score ligt tussen 7 en 13. Uit: Rijke e.a. concept manuscript 2020. 


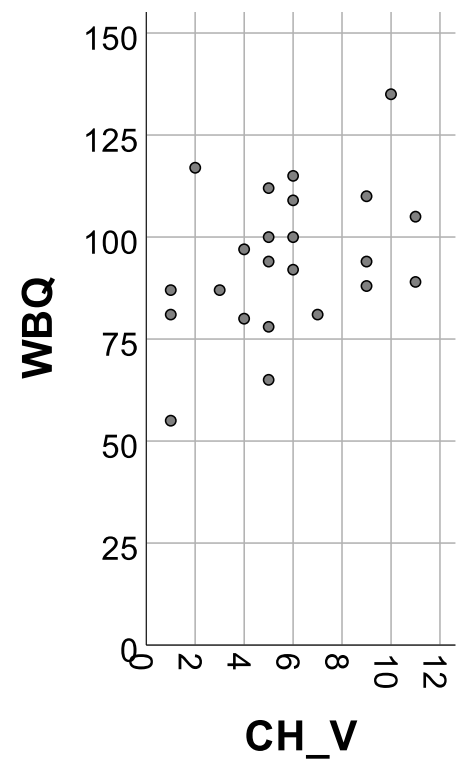

Figuur 5: De associatie tussen 'storage' Cijfers Herhalen Voorwaarts ( $\left.\mathrm{CH}_{-} \mathrm{V}\right)$ en Woordbegripsquotient (WBQ) bij kinderen met CI. Uit: Rijke e.a. Concept manuscript 2020.

\section{Conclusie}

In het kader van de titel van het symposium 'to hear or not to hear', blijkt voor kinderen met CI het horen 'an sich' een noodzakelijke maar niet voldoende voorwaarde voor de verwerving van complexe gesproken taalvaardigheden. Immers, voor kinderen met CI blijken de hoormogelijkheden in gunstige luisteromstandigheden aanzienlijk toegenomen, zodanig dat in principe de toegang tot gesproken taal geborgd is. Echter in rumoer is het spraakverstaan aanmerkelijk meer gecompromitteerd. Als gevolg hiervan moet in deze situaties meer luisterinspanning geleverd worden door kinderen met CI. Bovendien zijn als gevolg van de gedegradeerde auditieve input /of een onderliggend fonologisch storage probleem de fonologische representaties minder stabiel verankerd in het mentale lexicon. Ten gevolge van de verhoogde luisterinspanning en de fonologische problemen functioneert het werkgeheugen bij de kinderen met CI minder optimaal. Dit vormt een belemmering voor de verwerving van complexe taalvaardigheden.

\section{Dankwoord}

De auteurs danken de organisatie voor de uitnodiging en Rosanne Abrahamse, MSc voor het namens hen geven van de presentatie. 


\section{Referenties}

Baddeley, A. D., \& Hitch, G. (1974). Working Memory. In G. H. Bower (Ed.), Psychology of Learning and Motivation (Vol. 8, pp. 47-89): Academic Press.

Boons, T., De Raeve, L., Langereis, M., Peeraer, L., Wouters, J., \& van Wieringen, A. (2013a). Expressive vocabulary, morphology, syntax and narrative skills in profoundly deaf children after early cochlear implantation. Research in Developmental Disabilities, 34(6), 2008-2022. doi:10.1016/j.ridd.2013.03.003

Boons, T., De Raeve, L., Langereis, M., Peeraer, L., Wouters, J., \& van Wieringen, A. (2013b). Narrative spoken language skills in severely hearing impaired school-aged children with cochlear implants. Research in Developmental Disabilities, 34(11), 3833-3846. doi:10.1016/j.ridd.2013.07.033

Boothroyd, A. (1984). Auditory Perception of Speech Contrasts by Subjects with Sensorineural Hearing Loss. Journal of Speech, Language, and Hearing Research 27(1), 134-144. doi:doi:10.1044/jshr.2701.134

Bosman, A. J., \& Smoorenburg, G. F. (1995). Intelligibility of Dutch CVC syllables and sentences for listeners with normal hearing and with three types of hearing impairment. Audiology 34(5), 260-284.

Busch, T., Vermeulen, A., Langereis, M., Vanpoucke, F., \& van Wieringen, A. (2019). Cochlear Implant Data Logs Predict Children's Receptive Vocabulary. Ear and Hearing, Publish Ahead of Print. doi:10.1097/aud.0000000000000818

Cleary, M., Pisoni, D. B., \& Geers, A. E. (2001). Some measures of verbal and spatial working memory in eight- and nine-year-old hearing-impaired children with cochlear implants. Ear and Hearing, 22(5), 395-411. doi:10.1097/00003446-200110000-00004

Crosson, J., \& Geers, A. (2001). Analysis of narrative ability in children with cochlear implants. Ear and Hearing, 22(5), 381-394. doi:10.1097/00003446-200110000-00003

de Hoog, B. E., Langereis, M. C., van Weerdenburg, M., Knoors, H. E. T., \& Verhoeven, L. (2016). Linguistic profiles of children with CI as compared with children with hearing or specific language impairment. International Journal of Language \& Communication Disorders, 51(5), 518-530. doi:10.1111/1460-6984.12228

De Raeve, L., Vermeulen, A., \& Snik, A. (2015). Verbal Cognition in Deaf Children Using Cochlear Implants: Effect of Unilateral and Bilateral Stimulation. Audiology and NeuroOtology, 20(4), 261-266. doi:10.1159/000381003

Desjardin, J., \& Eisenberg, L. (2007). Maternal Contributions: Supporting Language Development in Young Children with Cochlear Implants. Ear and Hearing, 28, 456-469. doi:10.1097/AUD.0b013e31806dc1ab

Eisenberg, L., Kirk, K., Martinez, A., Ying, E., \& Miyamoto, R. (2004). Communication Abilities of Children With Aided Residual Hearing. Archives of Otolaryngology-Head \& Neck Surgery, 130, 563-569. doi:10.1001/archotol.130.5.563

Geers, A. E., \& Sedey, A. L. (2011). Language and Verbal Reasoning Skills in Adolescents With 10 or More Years of Cochlear Implant Experience. Ear and Hearing, 32(1), 39S48S. doi:10.1097/AUD.0b013e3181fa41dc

Geers, A. E., Strube, M. J., Tobey, E. A., Pisoni, D. B., \& Moog, J. S. (2011). Epilogue: factors 
contributing to long-term outcomes of cochlear implantation in early childhood. Ear and Hearing, 32(1 Suppl), 84s-92s. doi:10.1097/AUD.0b013e3181ffd5b5

Guo, L.-Y., \& Spencer, L. J. (2017). Development of Grammatical Accuracy in English-Speaking Children With Cochlear Implants: A Longitudinal Study. Journal of Speech, Language, and Hearing Research 60(4), 1062-1075. doi:doi:10.1044/2016_JSLHR-H-16-0182

Holzinger, D., Dall, M., Sanduvete-Chaves, S., Saldaña, D., Chacón-Moscoso, S., \& Fellinger, J. (2020). The Impact of Family Environment on Language Development of Children With Cochlear Implants: A Systematic Review and Meta-Analysis. Ear and Hearing, Publish Ahead of Print. doi:10.1097/aud.0000000000000852

Jacobs, E., Langereis, M. C., Frijns, J. H. M., Free, R. H., Goedegebure, A., Smits, C., . . . Vermeulen, A. M. (2016). Benefits of simultaneous bilateral cochlear implantation on verbal reasoning skills in prelingually deaf children. Research in Developmental Disabilities, 58, 104-113. doi:https://doi.org/10.1016/j.ridd.2016.08.016

Langereis, M., \& Vermeulen, A. (2013). Duidelijke meerwaarde van Cochleaire Implantatie - Het effect van CI op de taalontwikkeling, schoolse ontwikkeling en het welbevinden van ernstig slechthorende en dove kinderen. Logopedie, 85, 16-24.

Litovsky, R. Y., \& Gordon, K. (2016). Bilateral cochlear implants in children: Effects of auditory experience and deprivation on auditory perception. Hearing Research, 338, 76-87. doi:10.1016/j.heares.2016.01.003

Meyer, T. A., Svirsky, M. A., Kirk, K. I., \& Miyamoto, R. T. (1998). Improvements in Speech Perception by Children With Profound Prelingual Hearing Loss. Journal of Speech, Language, and Hearing Research 41(4), 846-858. doi:doi:10.1044/jslhr.4104.846

Moberly, A. C., Harris, M. S., Boyce, L., \& Nittrouer, S. (2017). Speech Recognition in Adults With Cochlear Implants: The Effects of Working Memory, Phonological Sensitivity, and Aging. Journal of Speech, Language, and Hearing Research 60(4), 1046-1061. doi:10.1044/2016_jslhr-h-16-0119

Moberly, A. C., Patel, T. R., \& Castellanos, I. (2018). Relations Between Self-reported Executive Functioning and Speech Perception Skills in Adult Cochlear Implant Users. Otology \& Neurotology 39(2), 250-257. doi:10.1097/mao.0000000000001679

Nittrouer, S., Caldwell-Tarr, A., \& Lowenstein, J. H. (2013). Working memory in children with cochlear implants: Problems are in storage, not processing. International Journal of Pediatric Otorhinolaryngology, 77(11), 1886-1898. doi:https://doi.org/10.1016/j.ijporl.2013.09.001

Peelle, J. E. (2018). Listening Effort: How the Cognitive Consequences of Acoustic Challenge Are Reflected in Brain and Behavior. Ear and Hearing, 39(2), 204-214. doi:10.1097/aud.0000000000000494

Pisoni, D. B., Kronenberger, W. G., Roman, A. S., \& Geers, A. E. (2011). Measures of digit span and verbal rehearsal speed in deaf children after more than 10 years of cochlear implantation. Ear and Hearing, 32(1 Suppl), 60s-74s. doi:10.1097/AUD.0b013e3181ffd58e

Rijke, W. J., Vermeulen, A., Willeboer, K., Knoors, H., Mylanus, E., Langereis, M., \& Van der Wilt, G. J. (In Progress 2020). Capability in Children With Hearing Loss: A Mixed Methods Study.

Sarant, J., Harris, D., Bennet, L., \& Bant, S. (2014). Bilateral versus unilateral cochlear im- 
plants in children: a study of spoken language outcomes. Ear and Hearing, 35(4), 396409. doi:10.1097/aud.0000000000000022

Svirsky, M. A., Teoh, S. W., \& Neuburger, H. (2004). Development of Language and Speech Perception in Congenitally, Profoundly Deaf Children as a Function of Age at Cochlear Implantation. Audiology and Neurotology, 9(4), 224-233. doi:10.1159/000078392

Tomblin, J. B., Harrison, M., Ambrose, S. E., Walker, E. A., Oleson, J. J., \& Moeller, M. P. (2015). Language Outcomes in Young Children with Mild to Severe Hearing Loss. Ear and Hearing, 36, 76S-91S. doi:10.1097/aud.0000000000000219

Torkildsen, J. v. K., Hitchins, A., Myhrum, M., \& Wie, O. B. (2019). Speech-in-Noise Perception in Children With Cochlear Implants, Hearing Aids, Developmental Language Disorder and Typical Development: The Effects of Linguistic and Cognitive Abilities. Frontiers in Psychology, 10(2530). doi:10.3389/fpsyg.2019.02530

Verhoeven, L., Keuning, J., Horsels, L., \& Boxtel, H. v. (2013). Wetenschappelijke verantwoording: Testinstrumentarium Taalontwikkelingsstoornissen. Cito, Arnhem.

Watson, D., Titterington, J., Henry, A., \& Toner, J. (2007). Auditory Sensory Memory and Working Memory Processes in Children with Normal Hearing and Cochlear Implants. Audiology \& Neuro-Otology, 12, 65-76. doi:10.1159/000097793

Weerdenburg, M. v., de Hoog, B. E., Knoors, H., Verhoeven, L., \& Langereis, M. C. (2019). Spoken language development in school-aged children with cochlear implants as compared to hard-of-hearing children and children with specific language impairment. International Journal of Pediatric Otorhinolaryngology, 122, 203-212. 